Millennials in the stacks: choices, habits and attitudes of frequent library users between the ages of 18 to 29 in Santiago, Chile

Authors:

Corresponding author:

Kristina Cordero

Literature Department

Faculty of Literature and Linguistics

Pontificia Universidad Católica de Chile

kcordero@uc.cl

ORCID ID: https://orcid.org/0000-0003-1566-2587

Co-authors

Pablo Chiuminatto

Literature Department

Faculty of Literature and Linguistics

Pontificia Universidad Católica de Chile

pchiuminatto@uc.cl

Sam Duncan

Institute of Education

University College London

sam.duncan@ucl.ac.uk

ORCID ID: https://orcid.org/0000-0002-9974-6464

Eglé Vera

Independent research assistant

aliasegle@yahoo.co.uk

ORCID ID: https://orcid.org/0000-0003-2384-4313 


\title{
Millennials in the stacks: choices, habits and attitudes of frequent library users between the ages of 18 to 29 in Santiago, Chile
}

\begin{abstract}
Libraries have been rethinking their collections and services in order to remain relevant for new generations. In Chile, adults between 20 and 36 are one-third of the population, yet they are underrepresented in the research on reading preferences and practices. Through a survey of 346 library users, librarian interviews and focus groups, this study sought to learn about library habits and preferences as well as literacy and cultural practices among 18 to 29 yearold library users in Santiago, Chile. Findings reveal a diversity of reading preferences, with an accent on genre fiction and nonfiction; an appreciation of the librarian as mediator and authority, a view of the library as a symbolic and material space; and a migration to the Internet for recommendations, access to books and spaces for new literacy practices. These initial findings underscore the importance of adapting libraries' collections and services as literacy practices evolve among young users in the $21^{\text {st }}$ century.
\end{abstract}

\section{Keywords}

Public libraries; Chile; user perception; millennials; reading habits; user experience; interviews; questionnaire; focus groups

\section{Introduction}


In our contemporary age of political, social and economic uncertainties, the relevance of the public library has suddenly come into sharp focus, as people all over the world need to develop critical abilities in order to absorb and evaluate the texts they read and the information they consume (Burnett \& Merchant, 2019). As Pateman (2011) notes, "public libraries can be key agencies for enabling social change and social justice." Others have gone so far as to suggest that the public library should be regarded as "a fundamental human right" (Halpin, Rankin, Chapman \& Walker, 2015) because of its pivotal role in democratizing access to culture and information. There is a broad consensus that libraries in the $21^{\text {st }}$ century are "more than just books" (Coppola, 2010), and scholars have identified the many ways libraries can and should evolve: by focusing on users' needs; understanding and engaging local communities; acknowledging and embracing diversity; adapting, expanding and innovating in the digital sphere (Agosto, 2016; Pateman, 2011; Summers \& Buchanan, 2018).

Though there is still some debate about the exact birth years that define "millennials," we place them roughly, as do Howe \& Strauss (1991, 2000) as those born between 1982 and 2002. In recent years, research into reading patterns among this group shows a diverse generation that is not necessarily as hooked on digital devices and platforms as the news media and the "digital native" discourse (Prensky, 2001) might suggest. Studies, rather, depict a generation of readers that use old and new media in different ways for different purposes (Botterill, Bredin, \& Dun, 2015; Kilian, Hennigs, \& Langner, 2012). Some studies have viewed millennial library users from the perspective of academic libraries (Lippincott, 2012; McDonald \& Thomas, 2006) and research needs (Abram \& Luther, 2004), while others take a broader approach (Botterill, Bredin, \& Dun, 2015; Sweeney, 2005), looking at how 
millennials use media in general. Some researchers invoke the need to strike a balance between "traditional library values" and the expectations of future generations (McDonald \& Thomas, 2006), while others have urged libraries to change as soon as possible because "millennials expect constant, rapid new services and far more options than they have been getting from traditional libraries" (Sweeney, 2005).

In summary, despite all the studies pointing to the need to update the definition of the library and the competencies of librarians, there is still a gap in terms of concrete, real-life information about the preferences and habits of young adult library users that would inform this transformation (Agosto \& Hughes-Hassell, 2005; Agosto, Pacheco Bell, Bernier, \& Kuhlmann, 2015).

\section{The library context in Chile}

Chile is among the OECD countries with the most significant economic growth in the past three decades. That said, Chile is also an extremely stratified, segregated society (Méndez \& Otero, 2018), which is reflected primarily in the gap between "haves" and "have nots" that affects economic aspects of young people's lives and their access to education and culture (Gayo, 2017). Understanding this reality is of critical importance for anyone seeking to understand how young people perceive and use libraries, and any other cultural or educational institution, for that matter.

In Chile, the public library is at a crossroads, for many of the reasons mentioned above, but also because of recent events nationwide, which have revealed a radical generational and social crisis, in which citizens of all ages, but particularly young people, are questioning the relevance of public and private institutions. This is both a challenge and an opportunity for 
libraries. Previous to this crisis, reading as a tool for education and social mobility was a typical focal point of policies and projects in the public and private sectors. The government has a National Policy on Books and Reading (Política Nacional del Libro y la Lectura, 20152020), a joint effort between the Ministries of Culture, Education and Social Development (Consejo Nacional de la Cultura y las Artes, 2015), as well as a National Plan for Books and Reading (Plan Nacional del Libro y la Lectura, 2015-2020), which aims to implement this policy through various strategies (Government of Chile, 2015). Within this framework, the National Public Library Service (SNBP, Servicio Nacional de Bibliotecas Públicas) plays a key role, through its collections and an array of reading promotion programs. However, little research to date has looked at the interests, habits and preferences of specific user groups within the libraries. According to the 2017 census, adults between the ages of 20 and 36 represent approximately $34.8 \%$ of the country's overall population, estimated at 7,112,808 inhabitants (Instituto Nacional de Estadística, 2018). However, little is known about their reading preferences and practices, and much less in relation to libraries.

The relationship between Chilean libraries and their users can only be understood in light of the national education system. The education sector is perennially concerned about stagnating student performance in reading on national and international standardized tests (Agencia de Calidad de Educación, 2017; Organisation for Economic Cooperation and Development, 2010, 2014, and 2016). Yet, outside of school teenagers and young adults in Chile have been actively engaging in new, multimodal, collaborative forms of literary consumption and expression — from manga, comics, and graphic novels to online reading and writing — that often go unrecognized by the "system." In other countries, as well, reading among young people often bears little relation to what is read in school (Duncan, 2014). 
Various sectors and actors in the fields of libraries and literacy (publishers, librarians, educators and literacy professionals) lack information on the age group in this study, which is not systematically evaluated as are primary and secondary school students. Though more general studies examine the reading practices of children and adults in general, we know of none to date that focuses exclusively on our chosen age group, which is relevant as the generation that has experienced most intensely the transition from print to digital technologies in all aspects of their lives.

Several recent studies in Chile have charted the public's perception of the country's library system. A 2011 study of library users reported that $38.3 \%$ of Chilean users between the ages of 18 and 25 and $46.2 \%$ of those between 26 and 36 attended the library "a few days a week," though since then no research focusing on this age group has come to our attention (DIBAM, 2011). Other studies have underscored the need to frame the library as a space for interdisciplinary reading and information gathering and reading promotion (Ramos Curd, 2012, 2013). In its most recent report, the National Public Library Service reported that the 15-29 age group represented 25\% of book loans in 2017 (SNBP, 2018). In 2014, a large-scale study of reading habits and practices among Santiago residents revealed a diversity of motivations and preferences. It raised the question about how Chileans perceive and use their public libraries (Mayol, 2014), prompting the need for research into more specific user groups.

With this in mind, this research project aims to explore how a diverse group of adults between 18 and 29 in the metropolitan area of Santiago, Chile, perceive and use libraries.

\section{Literature Review}


Studies from around the world demonstrate the ways in which public libraries continue to remain relevant to specific populations. A report by the Pew Research Center shows that in the United States, public libraries are very important for certain demographic groups (particularly veterans, low-income users and immigrants), who turn to them for a variety of needs, including literacy and language learning, job searching, technology training and everyday life information seeking (Agosto \& Hughes-Hassell, 2005; Horrigan, 2015). In Sweden, another developed country that has followed a different political and economic path, Atlestam \& Myrhe (2014) reached very similar conclusions in a study of library users in a multicultural urban area. In the UK, Summers and Buchanan (2018) present examples of successful library initiatives also directed at disadvantaged groups, noting that beyond providing books, libraries continue to make a difference for people by improving access to culture and information in a number of different ways. These efforts have helped to change people's perceptions about libraries and who they serve.

\section{The library as space: public, physical, symbolic}

As Alstad and Curry (2003) and many others have observed, libraries today must define strategies for reconciling the physical and the digital, which raises many questions: should the library be a multimedia entertainment center? A space for the free exchange of information? Around the world, a number of recent experiences shed light on possible paths into the future. In Spain, scholars acknowledge that libraries must diversify and expand their spaces and services to remain relevant (Alonso-Arévalo, 2016; Anglada, 2014). In Denmark and Norway, the four-space model of inspiration, learning, meeting and performance (Jochumsen et al., 
2016), has been used as a framework in various libraries. The Dokk1 library in Denmark is one emblematic example of how the physical library has been adapted to embrace a convergence of books, culture, technology and media, striking a balance between traditional uses and changing needs (Space for Change, 2015).

In the US and other countries, after the home and the work or school space, libraries can be significant "third places" (Oldenburg, 1999), where people develop a "sense of place" and community, and where civic life and democracy are supported (Lawson, 2004). Libraries certainly have a golden opportunity to shine as virtual third places for their users (Agosto, 2016), but their physical existence continues to be important for creating and sustaining communities, especially among teens and young people, who always need places for social and leisure activities (Agosto, Magee, Dickard, \& Forte, 2016; Agosto, Pacheco Bell, Bernier, \& Kuhlmann, 2015; Howard, 2011). In the UK, Sung, Hepworth, \& Ragsdell (2013) have responded to this need by proposing a library model based on community engagement and Agosto (2016) agrees, urging libraries to remain focused "on the people (not the stuff!)"

Finally, there is ample evidence that around the world, libraries are still valued as meaningful symbolic spaces (social, economic and cultural) (Halpin, et al., 2015; McCabe, 2001 in Alstad \& Curry, 2003). In the UK, surveys reveal a continued "strong sense of the epistemic role of libraries and their conception as safe, welcoming, community-owned spaces" (Appleton, Hall, Duff, \& Raeside, 2018; Law, 2013). Nevertheless, teenagers and young people have been said to perceive them as antiquated, rule-laden institutions that bear little relation to their autonomously technological lives (Agosto, Magee, Dickard, \& Forte, 2016). Clearly, the evolving attitudes of newer generations will change how libraries are 
valued in the years to come, and their perceptions will depend, at least in part, on how libraries adapt to their needs and desires, both expressed and implicit.

Libraries create spaces for their users in many ways. In "Cooking the books: what counts as literacy for young children in a public library," Helen Smith (2018) studies how literacy unfolds in libraries through the lens of Henri Lefebvre's "social space" theory (Lefebvre, 1991), which identifies three types of spaces: (1) the perceived space, a measurable, physical place brought alive through everyday practices; (2) the conceived space, of expectations, rules, and dominant ideologies; and (3) the lived space, which users adapt to serve their own purposes (Lefebvre, 1991, in Smith, 2018).

\section{The changing role of the librarian}

Librarians and those who work in the library play a key role in the experiences of library users (Valenza \& Stephens, 2015). The relationships that exist between librarians and library users can be delicate, complex, and difficult to understand-yet they are of paramount importance for the future of reading and information gathering. Studies from the late 1990s and early 2000s show that teens and young people have been reluctant to turn to librarians to meet their information needs (Latrobe \& Havener, 1997; Yohalem \& Pittman, 2003), and more recent research confirms this. As Derek Law (2011) points out, "If librarians wish to be real stakeholders in the teaching and learning process, this will require a fundamental rethinking and refashioning of the concept of user support. The key will be the ability to add value." Clearly, this is not just about librarians' abilities or lack thereof. Other factors contributing to this perception among teens and young adults include users' easy and fast access to 
information in our age, as well as the traditional system and structure of the library - the rules, the imposed silence, the late fees, hours, outdated material, and restrictions on technology access (Agosto \& Hughes-Hassell, 2005). Librarians can be catalysts to change these perceptions.

As Agosto and Hughes-Hassell (2005) note, “experienced librarians understand the importance of involving their patrons in the development and evaluation of the programs and services they offer." Public librarians are in an ideal position to educate their users about social media (Agosto, Purcell, Magee, \& Forte, 2015) and to support users' media literacy in a context that is ever-connected and constantly changing (Valenza \& Stephens, 2015). As Agosto (2016) concludes, if young people's negative perceptions of libraries and librarians can be reverted, libraries will be even better positioned to fulfill their mandate to impact the lives of current and potential users.

\section{Methodology}

\section{Context of this study}

Given the library context and research landscape described above, we designed a mixedmethods study using a convenience purposive sample of regular and frequent library users between the ages of 18 and 29, in the province of Santiago, Chile (Patton, 2001). We chose to study users of two distinct entities: (1) the public library system and (2) an independent library system run by a Chilean nonprofit foundation, both of which contain libraries with a significant number of users in this age group. With almost a century's worth of experience, the National Public Library System exercises a multifaceted role with cultural, patrimonial, educational, recreational and social objectives. Its collection of some 2.5 million books, in 
diverse formats and genres, is accessed via open stacks so that users may freely browse, read, and borrow if they are registered users. Across the country over two million titles are borrowed annually on the system's various platforms; some 700,000 of them in Greater Santiago (SNBP, 2018).

The second institution that participated in this study is Fundación la Fuente, a private nonprofit foundation, established in 2000, dedicated to "promoting and implementing educational and cultural activities that benefit, primarily, low-income communities in Chile" (Fundación la Fuente, 2018). In alliance with the Mall Plaza shopping center chain, the foundation runs ten libraries branded as Bibliotecas Viva (BV), all of which are located in Mall Plaza shopping centers. BV receives sponsorship from private companies, and functions on the basis of a nominal paid membership. With some 27,500 members, the BV system welcomed over one million people and loaned close to 250,000 titles in 2018 (Fundación la Fuente, 2019).

\section{Objectives}

The general objective of this study was to gain an understanding of the reading preferences and habits of regular library users in Santiago, Chile, between the ages of 18 and 29.

Specifically, we sought to explore and identify patterns in library users' decisions and preferences, to understand them better and gain insights that might help guide library acquisitions, improve existing users' experiences, and enable librarians and literacy professionals to envision ways to serve this segment both now and into the future. In addition to reading and library preferences, we also asked users about certain habits and preferences relating to cultural consumption and information-seeking, in order to contextualize their 
reading and library habits within a more general landscape of culture, communication and information.

\section{Research design}

The research team and partner institutions agreed on a mixed methods descriptive-qualitative study (Teddlie \& Yu, 2007) that would use purposive sampling in order to locate participants who were frequent library users between the ages of 18 and 29, with the goal of producing results that were "rich" with information (Patton, 2001), which we could not have gleaned from a random or representative sample (Maxwell, 1997; Miles \& Huberman, 1984; Palinkas, Horwitz, Green, Wisdom, Duan, \& Hoagwood, 2015). Working with the participating institutions, we considered loan and attendance statistics to determine the libraries that were most likely to have a "critical mass" of users in the study's target group, and used internal (unpublished) library reports and data to select libraries that represented a cross-section of communities in terms of urbanization (highly urbanized, suburban and rural) and socioeconomic levels, to include a range of demographic profiles within the sample (McCahill, Birdi, \& Jones, 2018). We identified sixteen public libraries and four Biblioteca Viva libraries in twelve of Santiago's 52 districts.

With the participating institutions we decided to collect three forms of data: (1) a questionnaire for library users; (2) interviews with librarians; and (3) focus groups with a selection of the questionnaire respondents. The purpose of the questionnaire was to access as much information as possible from as large a number of study participants as the research team and budget could manage, and gain the participation of those who might not have time 
to join a focus group or who might prefer the anonymity of filling in a questionnaire (Duncan \& Freeman, 2019; Duncan \& Paran, 2017). We chose to conduct interviews with librarians and focus groups with users in order to record the "written or spoken words and observable behavior" (Taylor, Bogdan, \& De Vault, 2015) of both our target user group as well as those who spend time with them, the latter group serving to contrast with and complement the information gathered from the library users themselves. Focus groups, moreover, offer the possibility of interaction and stimulating discussion where different views may be aired and assumptions challenged (Latham \& Gross, 2013). The focus groups were an important "final piece" of the study design as they allowed the team to probe into some of the tentative conclusions that emerged from the analysis of the survey. Ultimately this qualitative approach permitted an exploration of the how and why questions about the ways users might —or might not — wish to use their libraries, and the practical as well as symbolic views of libraries and their services (McCahill, Birdi, \& Jones, 2018).

\section{Data collection}

The data collection procedure involved three stages and produced questionnaire responses, notes from semi-structured interviews with librarians, and transcripts of two focus groups with library users between 18 and 29 years of age.

Stage One: Literature review and semi-structured interviews with librarians. In this phase we conducted a bibliographical review and began working with the two partner institutions to define the scope of the study. The research team, with the guidance of a specialist in survey methodology, formulated and piloted a series of questions and produced a questionnaire consisting of 14 multiple-choice and 2 open-response questions. Copies of the questionnaire were brought to the participating libraries; on each visit we held semi-structured 
interviews with the librarians on duty, explained the context and goals of the study, and asked them some general questions about the library, the staff, and the everyday experience in their library, as well as their reflections on their 18-29 year old users. This was an important step for two reasons: (1) it gave the librarians and their staff the background they would need to identify frequent users between the ages of 18 and 29 and invite those users to fill out the questionnaire (in Appendix 1); (2) these interviews generated information about the libraries and users from the perspective of library workers, which complemented the library users' self-reported survey data from Stage Two and the data from focus groups with users in Stage Three. These interviews also helped the research team think about questions to raise in the focus groups and comprised the first set of data. The notes were reviewed and coded for themes.

Stage Two: Survey. The objective of this phase was to generate a critical mass of self-reported data relating to users' occupations; on and offline reading and literacy practices; print book borrowing patterns; reading and other cultural interests and practices; desire for and participation in activities relating to books and reading, both on and offline; and opinions about the library's physical space and offerings. We did not include questions about digital or audio book borrowing patterns for two reasons: (1) the Biblioteca Pública Digital, Chile's Digital Public Library, which lends digital and audio books, is a separate institution within the library system with its own registry of users; and (2) we are currently conducting a study of those users.

The survey was administered, on hard copy, during May and June of 2017. Following this the research team collected, tabulated and analyzed the results. From this analysis the team defined the themes and topics to be explored in the following phase of focus groups. 
Stage Three: Focus groups. In order to gain a more nuanced understanding of some of the findings from the survey, the team held two focus group sessions with a subset of the survey participants. We chose to conduct focus groups rather than individual interviews because they would allow us to bring together multiple users with similar characteristics e.g., age range, interest in reading, and frequent library use (Appleton, et al., 2018)— and to probe deeper into more everyday aspects of the participants' reading habits and library use. Our hope with this material was to complement the survey data and "give a "voice" to users' experiences (Duncan, 2015).

We divided the survey participants into two age-based subgroups --18-24 years old and 25-29 years old — and selected eight participants, all of whom were frequent, "active library users" (Appleton, et al., 2018). Again, this was not a random group of library users, which would have been less useful to our study, for it would have included infrequent users (Appleton, et al., 2018). The focus groups were planned as semi-structured group interviews, and a list of open questions was drafted to prompt participants to expand on themes and issues that emerged from the survey results (Kvale, 2008).

The two focus groups, held on the same day, began with brief explanatory introductions of the research team, who read aloud the consent forms and responded to questions from the participants, who were informed of their role and rights in the context of the study. The focus groups, approximately forty minutes each, were audio recorded and transcribed, and then coded according to specific and general patterns as they emerged in the analysis. We adhered to Miles \& Huberman's (1984) concept of data reduction, coding our field notes, interview notes and focus group transcripts and then grouping those codes into categories. We then 
engaged in a thematic analysis which Braun and Clarke (2006) have cited as a useful tool for providing a "rich and detailed, yet complex, account of data;" this last phase allowed us to arrive at categories for discussion.

\section{Data analysis}

As we analyzed the survey results and focus group data we became aware of the need to examine a dimension of the library and reading experience that we had not, until then, considered closely. In both focus groups, the participants spoke repeatedly of how they valued the library space, the role of the librarian in their communities, and their everyday experience in those spaces. In this light, the work of Smith and Lefebvre, cited in the literature review, took on special relevance for it provided a structure through which to frame the data gathered, in the survey, librarian interviews and focus groups.

\section{Results}

What follows is a summary of: (a) quantitative-descriptive results and (b) qualitative results.

\section{Quantitative-descriptive results}

\section{Participants}

The total sample for the survey was 346 users (138 men and 208 women). Of this total, 210 (61\%) were public library users and 136 (39\%) were Biblioteca Viva users. 64\% were between the ages of 18 and 24, and $35 \%$ between the ages of 25 and 29. 
$33 \%$ of our survey participants stated they were full-time students; $29 \%$ worked full-time; $29 \%$ stated they worked and studied, while $9 \%$ were engaged in other activities. $83 \%$ stated they borrowed books for themselves; $8 \%$ for a relative or friend and $9 \%$ did not respond. As such, most of the responses in the questionnaire and the focus group reflect the habits and preferences of our participants and not those of "third parties."

\section{Access to reading}

The first part of the survey dealt with how much, how and why our study participants accessed books in the library. With regard to how much, female participants had borrowed an average of 3.7 books over the previous three months; men had borrowed an average of 2.7. By age group, study participants between 18 and 24 years old borrowed an average of 3 books per three-month period, and users between 25 and 29, an average of 3.9 books. As for how many books they had actually read in that same period of time, the average number of books women stated that they had read was 5.3; for men, the average was 4.1. By age range, average number of books read was 4.5 titles for the 18-24 age group, and 5.4 on average for the 25-29 year-olds. The survey also asked users how they gained access to reading material, aside from the library. As seen in Figure 1, the most popular source for books was free internet downloads; followed by loans or gifts; in-store purchases and, finally, online purchases.

\section{[INSERT TABLE 1 AND TABLE 1 CAPTION HERE]}

With respect to why, we asked participants the main reason they borrowed library books. The responses were: entertainment (39.9\%), studying (23.8\%); to broaden their general knowledge 
(21.3\%); vocational or professional improvement (9.2\%) and other reasons (5.8\%), as Figure 1 shows.

\section{[INSERT FIGURE 1 AND FIGURE 1 CAPTION HERE]}

We also asked our study participants how they chose their reading material, with a multiplechoice question in which they could mark as many options as applied. The 346 respondents provided us with 757 responses to this question, with 54\% stating that they selected books on the basis of a friend or relative's recommendation; $42 \%$ relying on reviews and articles in print publications; $35 \%$ on the recommendation of a teacher, professor or librarian; $31 \%$ used social media; and $25 \%$ on the basis of a connection to a television series, film or video.

\section{Reading preferences}

Regarding the types of books they read, we asked a multiple-choice question that allowed respondents to check as many alternatives as they wished. This question generated 1,597 responses. As Figure 2 shows, fiction genres (historical, romantic, sci-fi, fantasy, mystery, thrillers, terror, and crime) dominated, representing $55 \%$ of the responses, with $31 \%$ occupied by non-fiction (history, politics, philosophy, science and self-help). Only 5\% were interested in poetry, and 9\% in comics and graphic novels (admittedly a format and not a genre).

[INSERT FIGURE 2 AND FIGURE 2 CAPTION HERE] 
We then asked users if they were satisfied with their libraries' offerings; we also asked them to identify those genres that they felt were lacking in their libraries. In terms of overall satisfaction, $40.8 \%$ described themselves as "very satisfied" and 50\% as "satisfied." However, when asked what types of books they wanted to see more of, our 346 respondents recorded 457 responses, of which 57\% represented non-fiction categories (essay, science, self-help, history, politics and philosophy), and 36\%, fiction categories (sci-fi, fantasy, sagas, graphic novels and comics, short stories, romance, terror, mystery and crime). Poetry was the only genre for which nobody requested more titles. Figure 3 illustrates these responses.

\section{[INSERT FIGURE 3 AND FIGURE 3 CAPTION HERE]}

\section{Activities related to reading and writing}

The survey included two questions relating to (1) users' participation in activities associated with reading and books and (2) proposals for activities and services they would like to see in their libraries. To the first question, $86 \%$ of respondents stated they do not participate in activities relating to reading and books (in or out of the library), whereas the second question elicited 385 responses, of which $35.8 \%$ expressed a desire for more workshops and classes, from literacy and cultural activities to arts and crafts, professional training, civics, and sports.

\section{Reading and the Internet}

The questionnaire also addressed reading, the Internet and cultural practices. Firstly, users were asked what format they prefer when reading for pleasure (excluding the news). 54.3\% 
stated a preference for printed books; $36.1 \%$ enjoyed both print and digital formats; and $8.4 \%$ preferred digital formats (1.2\% did not respond).

When asked about their engagement in online literacy activities, 26\% stated that they either read and/or write fanfiction; and $20.8 \%$ write online fiction. $19.9 \%$ stated they play games, and an additional $5.5 \%$ specifically indicated role-playing games.

Though it was not the main focus of the study, we also included questions that probed into participants' habits and preferences with regard to information and entertainment in a broader sense, to gain insight into the cultural contexts in which the users' reading and library preferences are enmeshed. These questions, as such, helped us understand with greater nuance the preferences they expressed with regard to reading and libraries. The questions asked how often users watched traditional TV, watched paid TV services, went out to the movies, watched videos on YouTube, and downloaded or watched movies online. Participants' responses, via Likert scales of “always," "sometimes," and "never," seem to reflect national trends, with a preference for digital platforms (free or paid) for accessing content. For example, $18 \%$ of respondents indicated that they "always" watch open TV series, while $38 \%$ "always" watch television via paid services such as Netflix. Finally, 19\% stated they "always" go to the movies, while $26 \%$ stated that they "always" download or watch movies online, and $60 \%$ stated that they "always" watch YouTube videos.

\section{Qualitative results}

The qualitative analysis, gleaned from researchers' notes from interviews with librarians and the focus group transcripts, resulted in codes that were grouped into the following five categories (Braun \& Clarke, 2006) categories. 


\section{The library as a public space}

One of the first themes to emerge was the notion of the library as a public space that is used by many people for different reasons. In both the survey and focus groups, users made suggestions for improving infrastructure, from technological and electrical improvements to better bathrooms, the installation of a cafeteria, and longer hours. These recommendations show that these users want and need the library to be a comfortable space for reading, studying, and just being.

During the focus groups, security emerged as a practical problem that interferes in the operations of a place conceived for democratizing access to information and knowledge (IFLA/Unesco, 1994). "The issue of stealing" and "stealing and loss," frustrated our users' experience in the library. One participant observed that, because it is a place where books and services are accessible for free, the library often attracts people who "don't have a culture of literature, of taking care of things.”

Strategies aimed at security and control are enforced in many spheres of everyday life in Chile (stores with armed guards; cafés with hooks under the table to protect purses, etc.), but in the library, security measures feel at odds with the mission of providing free access to information and a welcoming environment for reading.

Manuel, during the focus group with 18-25 year-olds, explained it this way: ..so, homeless people start coming in from the plaza...sometimes there are students who need a computer and they can't use it, and they [the homeless 
people] are watching things on YouTube, on Facebook, and so in that sense they are being misused...

The "homeless people" and "students" are at cross purposes. Manuel clearly views this situation as what Lefebvre describes as the lived space or the counterspace. He feels students deserve the space more than the homeless. The rest of the group agreed with Manuel's comment, but the question hung in the air: do the homeless people have less of a right to the iInternet than students?

Field notes from the librarian interviews revealed more harmonious examples of coexistence. At one library in an outlying district of Santiago, that same convergence of diverse library users seemed positive, even an agent of change: as a group of adults participated in an Excel workshop, a volunteer finished up a Spanish class for Haitian immigrants. The librarian explained that because her library is the only community space in the district, it fulfills several roles. The research team observed this at other libraries, as well.

The library as a public space takes on special meaning in the four Bibliotecas Viva (BV) that participated in the study because they are located in malls. One librarian explained that many people go to the mall where her library is located "just to walk around." Since her library is close to the mall's food court, passersby sometimes wander into the library out of curiosity and end up staying. In another BV, many "regulars" are mall employees: from this perspective the mall library emerges as a valuable and practical cultural solution for employees at a shrine to consumerism. Moreover, the extensive list of activities on offer at all BV (from language classes to breastfeeding groups) reveals the vast world of possibilities that can emerge from the notion of a library both as and in a public space. 


\section{The library as a physical space}

The millennial users we surveyed and spoke with value the library not just for the books they may borrow but for the physical space it offers them. Both librarians and users spoke of the importance of the library as a place for studying — not surprising given that two thirds of the survey respondents identified themselves as students, either part or full time. Manuel said: "I go there because I study there...it's like going to the university," adding that "in the summertime, the library is like a cemetery"-just like universities.

In the focus groups, the topic of infrastructure, comfort and ambience were brought up. Tomás, in the 25-29 group, goes to his library "because of an issue of space and comfort...the atmosphere." He added that "I wouldn't mind a bit more space, like easy chairs and those kinds of things, to get comfortable." Manuel echoed this: "there's air conditioning, nobody bothers you, there are rooms where you can study, blackboards." Pedro, in the 25-29 group, preferred his library because of the security but also because "they let you bring things inside, which really suits me, [in other libraries] they don't let you bring a bag, or a bottle of water..."

These users need spaces that adapt to their personal needs. References to furniture suggest a desire to settle into the library, almost replicating what one has (or would like to have) at home. This, combined with security concern, reveals users' expectations of the library to be a welcoming space where they may be relaxed and without worries, in order to focus on the activity of reading, whether for pleasure or study. 


\section{The library as a symbolic space}

In both focus groups, participants described close bonds with their libraries, evoking the value they ascribe the library as an institution. Florencia, in the 18-24 group said:

My family always instilled in me the importance of reading a lot; I still remember the first book they gave me - I read it in one night, one Christmas Eve. And ever since then, since that first book, I've always been interested in going to the library...that book was a fantasy novel, and after that I started reading a lot of fantasy. I still do, even now [...] I've always been fascinated by libraries, wanted to go to libraries...I've been going regularly for several years. The due date rolls around and I go back to take out more books.

Jessica, a student and mother of a motivated young reader, spoke of the symbolic value of the library as a place for self-improvement: "I'm studying to be a nursery school teacher and so I look for books about that, to grow, sort of...I want to learn more and so I look for books on all the topics that come up in class." Nadia, in the 25-29 group, also a mother, often uses the Bibliobus in her district to borrow books for her daughter, who "eats up every book I give her-I'm very proud of that."

For these young mothers the library serves a double purpose: it is a space for introducing their children to reading, and for satisfying their own reading needs, professional and personal. Jessica's words effectively express the symbolic value she ascribes to both reading and the library: 
...but I also just take books out for fun, too....for him [her son] I take out stories, but I let him pick them, because children become excited about reading when they are encouraged to read from a young age, that's what's so good about this... as for me, I'm reading a saga right now...fantasy books...

During one of our initial interviews, the head librarian of one public library told us about one of the most meaningful recent projects for her and her team, a storytelling series that the library ran in conjunction with the schools in her district. In this light we see the librarian's appreciation of the library as more than just a physical space that provides books: as an institution that contributes to the education of its users, whether or not they are users that literally pass through the doors of the physical library itself. In another district, another librarian told us about a project that brought the library to schools through Bibliobuses, again underscoring the project as one of her most satisfying and valuable she had worked on that year. In other districts where the library buildings had been recently rebuilt and/or refurbished, the librarians told us that after the reopenings, they noted an increase in reading and in the local residents' identification of the library as a community space, and they attributed this partly to the rejuvenation and party to their libraries' central locations (near metro stations or central plazas). 
In both focus groups the topic of choosing books and the role of the librarian generated a very dynamic and stimulating conversation, in part because the participants had very wide-ranging opinions about the kind of attention they wanted from their librarians. The conversation revealed how intimate, personal, and idiosyncratic the book selection process is, and the delicacy and care that is required when intervening in that process.

Nadia, for example, had this to say: "I've always felt that choosing a book has to be something super intimate...I think that the consulting librarian should be able to say 'I know what kind of books you like, this just came in...take it.' Some librarians don't do that." She then told us about a book that an ex-boyfriend had given her, by an author she hadn't read: "I devoured all his books in two months," she said, confessing that the bond with her exboyfriend was at least partly responsible for her fascination.

In this same group, other participants categorically rejected any intervention on the part of a librarian: "I'm really reserved, really shy —I pick my books," Ignacia said. Pedro, though he liked to browse and find books on his own via trial and error, did recognize the role of the librarians at his library: "what I do value about them.... is that they never tell you that you can't read something; [they wouldn't say] 'hey, what do you want that for? It's not for you.'” These comments suggest a tension between the desire to read, a solitary approach to picking books, and a sensitivity to the opinion of the librarian. Here, we may begin to build a notion of the interpersonal and other factors that come into play in the relationship between librarian and user.

In the 18-24 focus group, there was more consensus regarding the job of library staff: 
Kristina: What is your impression of the librarian, or the people who work in the library?

Sebastián: Nah...they're just there for checking out books.

Kristina: The transaction?

Sebastián: Yes, I guess. They just do their job, that's it.

Manuel and Florencia nodded. Florencia added that in her library there were plenty of people working but not necessarily focused on helping users find books or even talking to users, and emphasized the need to have someone "get out from behind the desks" to interact with library users. Several members of this group agreed, and Manuel added "they should be recommending books...for the young people. Because I see a lot of young people that go in and kind of get lost."

The relationship between librarian and user seems to flow especially well when the reading is related to studies or work. Jessica, for example, described a close, friendly relationship with her librarian: "there's one [librarian] in particular, we get along really well—she also studied preschool education and she's always telling me 'you might want to take a look at this book. She's always recommending books - things for fun and for my work." Jessica and her librarian established a personal connection based on their common professional backgrounds, and that bond deepened over time.

\section{Communication media as mediators for reading}


In Chile, public and private institutions have placed great emphasis on mediation as a key tool for promoting reading. Generally reading mediators are thought of in terms of teachers (preschool, primary and secondary), librarians, storytellers, etc. But books, films, software programs and other devices and tools can also be mediators in the process of acquiring knowledge through reading (Brown, Ash, Rutherford, Nakagawa, Gordon, \& Campione, 1997). During the focus groups, we learned that some of our participants' reading practices crossed paths with their other media activities, particularly their explorations and experiences online, which contrasted with their more rigid literacy experiences in school.

Ignacia said that films had influenced her reading choices; watching films like Harry Potter and Matilda led her to read the books on which they were based. Tomás had a similar, perhaps even more remarkable story:

Movies were what brought me to reading, because in school reading just horrified me... and since I like looking up information on the Internet, and I was very interested in the mafia, one day I discovered that The Godfather was a novel, and I decided to read it, and that was the first book I ever read just because I wanted to ... and I loved it.

Others in Tomás' group described similar, positive experiences of engaging in reading after watching TV series and movies, from Game of Thrones to Stephen King, Forrest Gump and Trainspotting. Several participants talked of seeing a movie or TV show and then searching for the original book in the library. If the search was not successful, many turned to the Internet to download what they were looking for. Tomás, for example, said he was "bad 
reading in digital [format]" but that he did so when he had no other way to access a book he wanted to read.

Several of Tomás' companions nodded in assent when he described his lack of motivation to read in school, and cited the type of books, the lack of choice, and teachers' methods as some of the reasons they had been turned off by reading during primary and secondary school. According to Ignacia, "in school I hated poetry, I never liked the way they [her teachers] presented poetry to us." Years later, she attended a poetry workshop that turned her opinion around. Both groups agreed emphatically that teachers and other school authorities applied poor criteria when selecting reading material for students, making uninspired choices from the so-called literary canon that Nadia described as "obvious government-issue books," which tended to undermine whatever motivation they might have felt for reading.

Some parallels emerged when the focus group conversations turned to literary activities in the library. When asked about reading clubs or writing workshops, participants described a range of experiences that were less than satisfying, possibly because of a tension between the intimate, solitary nature of reading and the act of sharing that with a group. Tomás remarked that he had participated in a book club but felt out of sync with the others in the group and their interests, and stopped attending because he felt a kind of "literary bullying." Pedro, nodding, said "I think I'm part of that percentage of people who really like to do things on their own, read...[like] people who go to the movies alone...I don't feel comfortable sharing in a very general group."

Internet, on the other hand, emerged as a realm of possibilities for literary activity that both survey respondents and focus group participants seemed to value, identifying Facebook 
and online reading and writing sites like Wattpad as well as those dedicated to fanfiction. Tomás explained it: “...if you think about it, online there are lots of reading groups...on Facebook there's a need to say 'hey, you know I loved that,' and that there's someone else who can respond, 'yeah, and this other part is awesome too.'”

The digital format would seem to help in breaking the barrier of shyness or distance that some people expressed with respect to sharing opinions with strangers; Internet also opens wide the array of options. Other participants pointed to this and other aspects, such as the wider universe of people, countries and interests to be found online: "there are science fiction groups, groups of doctors, groups that read fantasy novels...writers groups... and you don't have the limitation of 'I live in Spain so I can't help you." In this sense digital spaces seem to offer more flexibility, specificity and options than what would be possible in on-site activities, since readers can find groups almost tailor-made for their interests and needs, which might seem more attractive than adapting to the structure of a conventional in-person reading or writing club.

Finally, the online space emerges not only as a space for literacy practices but as a source of information, or "recommender," as Sebastián put it: "When you're curious about a book... [you can] look for it online, look up information about it, and then look for the book in the library."

\section{Discussion}

\section{Reading preferences}


From the survey and focus group results a picture — albeit incomplete — begins to emerge, suggesting a universe of users with a variety of purposes, tastes and habits with regard to reading. We see this diversity in the distribution of reading preferences, with an emphasis on fiction categories and a small but potentially relevant percentage of library users interested in graphic novels and comics. Non-fiction emerges as a category to watch, since the majority of suggestions for improving collections fell into this category, suggesting an opportunity to expand and diversify non-fiction offerings. Interestingly, users seemed content with the fiction on offer.

Another notable result was the small number of users interested in poetry; not a single user felt that his/her library needed more poetry books. The focus group participants connected this lack of interest to the type of poetry that was selected for them and the way it was taught in primary and secondary school. Considering that Chile calls itself "the country of poets" (thanks to three Nobel prize-winning poets), it would be meaningful to probe deeper into the reasons that poetry awakens so little interest among certain young people.

\section{The role of the librarian and the library staff}

Both the survey and the focus groups underscored the role of the librarian. The survey findings show that our users value recommendations, especially that of the librarian, suggesting trust and credibility as decisive factors. This leads to the librarian's potential as a mediator. The focus groups did, however, expose the complexity and diversity of individuals who arrive at the library. Some users want conversation, suggestions and help from their 
librarians, while others, either timid or more reserved, prefer getting recommendations from family, teachers, friends and the Internet.

Some people in the focus groups expressed views of the librarian as an authority figure, a gatekeeper, which might explain, at least partly, why some users gravitate to the Internet for inspiration and recommendations. That said, no one single site such as Goodreads emerged as a typical source, possibly because there is no one site in the Spanish speaking world that has developed a community like that of Goodreads. Given this scenario, and the sensitive nature of sharing thoughts and ideas relating to reading, it would seem important, in this context, to review the way relationships unfold between library staff and the people that enter the library—some of whom don't always stick around long enough to find a book, as one focus group member observed. More specific training of library staff, in reading mediation as well as user interaction and support, might help to cultivate and strengthen the community environment that study participants value and seem to yearn for. In addition, other strategies such as "Readers' Advisory" and other less personal forms of recommending books (thematic exhibits of books, staff picks, etc.) also might help to connect with those users who do not wish to engage in such personal contact with librarians.

\section{Activities relating to reading and books}

At first glance, the survey produced one set of seemingly contradictory results in this area: (1) a low percentage of respondents who regularly attended activities relating to reading and books in and out of the library context; and (2) a high percentage of respondents who 
expressed the desire for more literary and cultural activities at their libraries. This contradiction seems to jibe with the Public Libraries' 2017 report which stated that $42 \%$ of all library users who created an initial web registration in order to participate in computer-based activities were in the 15-29 year old age group, but only $12 \%$ actually engaged in online sessions and 4\% participated in some form of training class (SNBP, 2018). Likewise, our survey and focus group results show that users certainly see the library as a place to participate in activities (related to reading as well as other pursuits), and would like to do so but, for some reason, do not always do so. The quantity and range of proposals for possible activities suggests that users do see the library as a communal space as well as a space for learning (which jibes with the libraries' stated mission), yet the data on attendance shows that there is a real gap between the activities users might like to see in their libraries and the activities on offer that they participate in. The focus group data suggest a few possible explanations for this trend:

(a). Users' perception and use of the library as a place to study rather than a place to share experiences of reading for pleasure and other leisure experiences.

(b). Users' shift toward the digital format for leisure and entertainment. Both the survey and focus groups showed that users are making use of opportunities to explore reading, writing and other literacy practices online, outside of the library context. 
(c). Lack of time and/or interest in going to physical libraries to participate in literary activities that don't meet specific interests, which users may be able to satisfy in online activities unrelated to the library.

When describing his yearlong involvement in a library-run book club, one focus group participant said that he eventually left the club because of "literary bullying" from the other members. Research on book clubs show that the most satisfying and successful book club experiences result from a harmonious combination of literary interests, personalities, and goals (Freeman, 2005; Newman, 2017). Much like the relationship between librarians and their users, the interpersonal dynamic of the book club (and any reading-related activities) is clearly more complex than it might appear; it's more than just picking a weekly book to read and scheduling a meeting time.

\section{The media as mediators of reading}

Our data helped compose a rich, nuanced portrait with regard to the role that the Internet and non-print media play in reading practices. Survey respondents preferred the print format over digital platforms for reading: however, the $46 \%$ that reads in both print and digital formats is high and might increase over the next few years. The preference for print over digital books/texts is almost anecdotal given the broader context of reading and media consumption. The influence of media and the Internet is more complex than a simple preference of one format over another. The results show that the Internet resolves certain practical issues relating to reading, by giving people access to texts that are otherwise inaccessible, whether ultra-recent publications not yet available in print in Chile, or out-of-print books. 
The notion of the media as mediators of reading emerged in the survey and the focus groups. Our participants turned to both new and old media when selecting what to read, confirming that reviews in both digital and print media remain a relevant source of recommendations. In terms of reading preferences, almost a third of our respondents consumed sagas adapted for television or film. Several focus group participants stated that the movies had sparked an interest in reading that they had not felt in school.

Our results also showed that the typical "digital versus print book" debate is an oversimplification of the mixed media practices young people engage in today. For example, users might read a blog post about a book, take the book out of the library, share their opinion of the book on Facebook, and then go on to recommend it to a friend. The "extra" questions we asked participants, about their cultural/entertainment activities outside of the library and books, rounded out this picture even more: many read and write fanfiction online, watch videos on YouTube, download movies, watch television via paid services like Netflix, and continue to go to the movies. The data from those questions reveal engagement with a range of formats and genres for culture and entertainment; books are just one of several options they have.

The study participants made it clear that readers move back and forth between physical and virtual spaces, reading and other forms of entertainment, without adhering to strict, linear, predictable paths, a trend that is reflected in the research on millennials' media use in other countries (Botterill, et al., 2015; Ofcom, 2012, 2013). Readers, writers, editors and publishers are still exploring the different possible marriages of content and form, experimenting with tools, formats, platforms, and devices to receive and transmit information via the written 
word. The future of reading and writing clearly has yet to be written, and libraries' role in that future remains both an open question and an opportunity.

\section{Limitations}

In this study there are a number of limitations to acknowledge and implications to consider when looking toward possible future work.

Because this study used a purposive sampling method, the results are not representative of 18-29 year-olds in Santiago, much less other national contexts (rural, regional, semi-urban, etc.). The data were gathered through interventions at specific moments in time rather than through repeated sessions over time. While we did find connections between our results and those from studies in other countries, there are multiple factors (socio-economic, political, educational, cultural, health and social justice) that converge to make everyday experiences in Chile very different to the experiences of people in other countries. As such, readers should be very cautious about drawing parallels that may not exist.

\section{Implications and Future Work}

Given the high percentage of users who described themselves as students (full or parttime), as well as our conversations with librarians and focus group participants, a future study might explore the degree and the ways in which libraries are used for professional and academic purposes, including job-seeking. This complements the Pew Research Center's findings with regard to library use (Horrigan, 2015). 
Other specific topics that emerge from this study are: poetry instruction and mediation among secondary schoolers and young adults; the incipient popularity of graphic and comic formats; reading communities, book clubs, and reading/writing workshops, in libraries and other venues; transmedia literacy practices among young adults; and different dimensions of online reading. The study participants' limited engagement with on-site activities at the libraries suggests that perhaps their reading preferences are satisfied outside the libraries. In this light, a study on millennials' reading and leisure activities outside of the library would help to create a fuller picture of their reading and cultural interests beyond the confines of the library. This paper hopes to offer some initial steps and insights into these areas.

\section{Funding Details}

This work was supported by the Fund for Books and Reading, Ministry of Culture, Arts and Heritage (Fondo del Libro y la Lectura, Ministerio de las Culturas, las Artes y el Patrimonio), Government of Chile, Grant 411914, as well as the Literature Department and Continuing Education Department, Pontificia Universidad Católica de Chile.

\section{Disclosure Statement}

No potential conflict of interest was reported by the authors.

\section{Data Availability Statement}

The data used for this paper is available on request due to privacy/ethical restrictions. The data that support the findings of this study are available on request from the corresponding 
author. The data are not publicly available due to restrictions contained in the consent forms signed by participants.

\section{References}

Abram, S., \& Luther, J. (2004). Born with the Chip: The next generation will profoundly impact both library service and the culture within the profession. Library Journal, 129(8), 34.

Agencia de Calidad de Educación (2017). Resultados Educativos 2016. Santiago, Chile: Ministerio de Educación.

Agosto, D. E. (2016). What's next in US public library services for teens? A peek into a promising future. Public Library Quarterly, 35(4), 344-350.

https://doi.org/10.1080/01616846.2016.1251806.

Agosto, D. E., Pacheco Bell, J. P., Bernier, A., \& Kuhlmann, M. (2015). “This is our library, and it's a pretty cool place": A user-centered study of public library YA spaces. Public Library Quarterly, 34(1), 23-43. https://doi.org/10.1080/01616846.2015.1000777 
Agosto, D. E., \& Hughes-Hassell, S. (2005). People, places, and questions: An investigation of the everyday life information-seeking behaviors of urban young adults. Library \& information science research, 27(2), 141-163. doi:10.1016/j.lisr.2005.01.002

Agosto, D. E., Magee, R. M., Dickard, M., \& Forte, A. (2016). Teens, technology, and libraries: An uncertain relationship. The Library Quarterly, 86(3), 248-269. https://doi.org/10.1086/686673

Agosto, D. E., Purcell, M., Magee, R. M., \& Forte, A. (2015). Teens, libraries, and social media: Myths and reality. Public Library Quarterly, 34(4), 318-327. https://doi.org/10.1080/01616846.2015.1106892.

Alonso-Arévalo, J. (2016). La biblioteca en proceso de cambio. BiD: textos universitaris de biblioteconomia i documentació, (36).

http://eprints.rclis.org/29504/1/La\%20biblioteca\%20en\%20proceso\%20de\%20cambio.pdf

Alstad C., \& Curry, A. (2003) Public space, public discourse and public libraries. LIBRES 13(1). Available at: http://www.libres-ejournal.info/wpcontent/uploads/2014/06/Vol13_I1_pub_space.pdf (accessed 20 September 2019). 
Anglada, L. (2014). Are libraries sustainable in a world of free, networked, digital information?//i Son las bibliotecas sostenibles en un mundo de información libre, digital y en red?. El profesional de la información, 23(6), 603-611.

Appleton, L., Hall, H., Duff, A. S., \& Raeside, R. (2018). UK public library roles and value: A focus group analysis. Journal of Librarianship and Information Science, 50(3), 275-283. https://doi.org/10.1177/0961000618769987

Atlestam, I., \& Myhre, R. (2014). Needs, reads and possibilities in a suburban library in a multicultural setting. In: IFLA World Library and Information Congress: 80th IFLA general conference and assembly. Lyon, France

Botterill, J., Bredin, M., \& Dun, T. (2015). Millennials' media use: It is a matter of time. Canadian Journal of Communication, 40(3).

Braun, V., \& Clarke, V. (2006). Using thematic analysis in psychology. Qualitative research in psychology, 3(2), 77-101. http://dx.doi.org/10.1191/1478088706qp063oa

Brown, A. L., Ash, D., Rutherford, M., Nakagawa, K., Gordon, A., \& Campione, J. C. (1997). Distributed expertise in the classroom. In G. Solomon (Ed.), Distributed cognitions: Psychological and Educational Considerations (pp. 188-228). Cambridge: Cambridge University Press. 
Burnett, C., \& Merchant, G. (2019). Revisiting critical literacy in the digital age. The Reading Teacher, 73(3), 263-266.

Consejo Nacional de la Cultura y las Artes (2015) Política Nacional del Libro y la Lectura 2015-2020.

https://www.cultura.gob.cl/wp-content/uploads/2014/08/politica-libro-lectura-2015-2020.pdf

Coppola, G. (2010). Library as the Third Place. Florida Libraries, Fall 2010, 14-15.

Dirección de Bibliotecas, Archivos y Patrimonio (DIBAM), (2011). Estudio de percepción de usuarios DIBAM 2011. Santiago, Chile: Sistema Nacional de Bibliotecas Públicas.

Duncan, S. (2014). Reading for pleasure and reading circles for adult emergent readers: insights in adult learning. Leicester: NIACE.

--- (2015). Reading aloud in Lewisham: an exploration of adult reading-aloud practices. Literacy, 49(2), 84-90.

Duncan, S., \& Paran, A. (2017). The effectiveness of literature on acquisition of language skills and intercultural understanding in the high school context. A research report for the International Baccalaureate Organisation.

Duncan, S., \& Freeman, M. (2019). Adults reading aloud: a survey of contemporary practices in Britain. British Journal of Educational Studies. doi:10.1080/00071005.2019.1610555. 
Freeman, S. (2005). End of Discussion: Why I'm leaving my book group. American Scholar, 74(1), 138-142.

Fundación la Fuente (2018). Quiénes somos. Retrieved March 23, 2018, from http://www.fundacionlafuente.cl/quienes-somos/.

--- (2019). Informe de Gestión de Biblioteca Viva. Santiago, Chile: Fundación la Fuente.

Gayo, M. (2017). Exploring cultural disengagement: The example of Chile. Cultural Sociology, 11(4), 468-488. Ds:O//dIo: i1.o0r.g1/107.171/177/4197499795751571772277441

Gobierno de Chile (2015) Plan Nacional del Libro y la Lectura 2015-2020.

http://plandelectura.gob.cl/wp-content/uploads/2016/12/Plan-Nacional-Lectura-web-6-12$\underline{2016 . p d f}$

Halpin, E., Rankin, C., Chapman, E. L., \& Walker, C. (2015). Measuring the value of public libraries in the digital age: What the power people need to know. Journal of Librarianship and Information Science, 47(1), 30-42.

Horrigan, J. B. (2015). Libraries at the Crossroads: The public is interested in new services and thinks libraries are important to communities. Washington, DC: Pew Research Center.

Howard, V. 2011. What do young teens think about the public library? The Library 
Quarterly 81 (3):321-44. doi:10.1086/660134 .

Howe, N., \& Strauss, W. (1991). Generations: The history of America's future, 1584 to 2069. New York: William Morrow.

---- (2000). Millennials rising: The next great generation. New York: Vintage.

IFLA/Unesco (1994). Public Library Manifesto. The Hague: IFLA/Unesco.

Instituto Nacional de Estadística (INE) (2018). Resultados Censo 2017. Santiago, Chile: Ministerio de Economía.

Jochumsen, H., Skot-Hansen, D., \& Rasmussen, C. H. (2016). The four spaces of the public library. In The End of Wisdom?, 39-44, Chandos Publishing.

Kilian, T., Hennigs, N., \& Langner, S. (2012). Do Millennials read books or blogs?

Introducing a media usage typology of the Internet generation. Journal of Consumer Marketing, 29(2), 114-124.

Kvale, S. (2008). Doing interviews. London: Sage. 
Latham, D., \& Gross, M. (2013). Instructional preferences of first-year college students with below-proficient information literacy skills: A focus group study. College \& Research Libraries, 74(5), 430-449.

Latrobe, K., \& Havener, W. M. (1997). Information-seeking behavior of high school honors students: An exploratory study. Journal of Youth Services in Libraries, 10, 188-200.

Law, D. (2011). Library landscapes: digital developments. Libraries and Society: Role, Responsibility and Future in an Age of Change, 361-77.

Law, D. (2013). The universal library: realising Panizzi’s dream. In A handbook of digital library economics (pp. 233-246). Chandos Publishing.

Lawson, K. (2004). Libraries in the USA as traditional and virtual "third places." New Library World, 105 (1198/1199), 125-130.

Lefebvre, H. (1991). The Production of Space. Translated by D. Nicholson-Smith. Oxford: Blackwell.

Lippincott, J. (2012) Information Commons: Meeting Millennials’ Needs, Journal of Library Administration, 52 (6-7), 538-548, DOI: 10.1080/01930826.2012.707950. 
Maxwell, J. (1997). Designing a qualitative study. In L. Bickman \& D. J. Rog (Eds.)

Handbook of applied social research methods (pp. 69-100). Thousand Oaks, CA: Sage.

Mayol, A. (2014). La lectura en espacios públicos de Santiago. In Anales de la Universidad de Chile, 6, 83-100.

McCabe, R. (2001). Civic Librarianship: Renewing the Social Mission of the Public Library. Lanham, MD: Scarecrow Press.

McCahill, D., Birdi, B., \& Jones, R. B. (2018). Investigating the public response to local government decisions to reduce or remove public library services. Journal of Librarianship and Information Science. https://doi.org/10.1177/0961000618768028

McDonald, R. H., \& Thomas, C. (2006). Disconnects between library culture and millennial generation values. Educause quarterly, 29(4), 4.

Méndez, M. L., \& Otero, G. (2018). Neighbourhood conflicts, socio-spatial inequalities, and residential stigmatisation in Santiago, Chile. Cities, 74, 75-82.

http://dx.doi.org/10.1016/j.cities.2017.11.005 
Miles, M. B., \& Huberman, A. M. (1984). Drawing valid meaning from qualitative data: Toward a shared craft. Educational Researcher, 13(5), 20-30.

Newman, J. (May 11, 2017). Dear Book Club: It's you, not me. New York Times, 11 May 2017.

Ofcom. (2012). Adults' media use and attitudes report. URL: http://stakeholders.ofcom .org.uk/binaries/research/media-literacy/media-use-attitudes/adults-media-use-2012.pdf [retrieved November 22, 2019].

Ofcom. (2013). Communications market report 2013. URL: http://stakeholders.ofcom.org.uk /binaries/research/cmr/cmr13/2013_UK_CMR.pdf [retrieved November 22, 2019].

Oldenburg, R. (1999). The great good place: Cafes, coffee shops, bookstores, bars, hair salons, and other hangouts at the heart of a community. Boston, MA: Da Capo Press.

Organization for Economic Cooperation and Development (OECD). (2010) PISA 2009 Results: What Students Know and Can Do - Student Performance in Reading, Mathematics and Science. PISA, OECD Publishing. 
Organisation for Economic Cooperation and Development (OECD) (2014). PISA 2012 Results: What students know and can do-student performance in mathematics, reading and science (Volume I, Revised edition, February 2014), PISA, OECD Publishing.

Organisation for Economic Co-operation and Development (OECD). (2016). PISA 2015 Results in Focus.

Palinkas, L. A., Horwitz, S. M., Green, C. A., Wisdom, J. P., Duan, N., \& Hoagwood, K. (2015). Purposeful sampling for qualitative data collection and analysis in mixed method implementation research. Administration and Policy in Mental Health and Mental Health Services Research, 42(5), 533-544.

Pateman, J. (2011). Public libraries, social class and social justice. Information, Society and Justice, 4(2), 57-70.

Patton, M.Q. (2001). Qualitative research and evaluation methods, 3rd edition. Sage Publications.

Prensky, M. (2001). Digital natives, digital immigrants. On the Horizon, 9 (5), 1-6.

Ramos-Curd, E. (2012). Bibliotecas Públicas en Chile: antecedentes, buenas prácticas y proyecciones. Serie Bibliotecología y Gestión de Información, (73). Santiago (Chile): Universidad Tecnológica Metropolitana. 
---- (2013). Estrategias para alcanzar nuevos lectores. Serie Bibliotecología y Gestión de Información, 80. Santiago (Chile): Universidad Tecnológica Metropolitana.

Sistema Nacional de Bibliotecas Públicas (2018). Boletín estadístico del Servicio Nacional de Bibliotecas Públicas, Programa Biblioredes, 2017.

http://www.bibliotecaspublicas.cl/624/articles-84576_archivo_01.pdf

Smith, H. V. (2018). Cooking the books: what counts as literacy for young children in a public library?. Literacy 52(1), 31-38. https://doi.org/10.1111/lit.12121

Space for Change: Dokk1_Aarhus' new meeting place. (2015). Aarhus, Denmark: Aarhus Communes Biblioteker.

Summers, S., \& Buchanan, S. (2018). Public libraries as cultural hubs in disadvantaged communities: developing and fostering cultural competencies and connections. The Library Quarterly, 88(3), 286-302. https://doi.org/10.1086/697707

Sung, H. Y., Hepworth, M., \& Ragsdell, G. (2013). Investigating essential elements of community engagement in public libraries: An exploratory qualitative study. Journal of Librarianship and Information Science, 45(3), 206-218.

https://doi.org/10.1177/0961000612448205 
Sweeney, R. T. (2005). Reinventing library buildings and services for the millennial generation. Library Administration and Management, 19(4), 165-176.

Taylor, S. J., Bogdan, R., \& DeVault, M. (2015). Introduction to qualitative research methods: A guidebook and resource. John Wiley \& Sons.

Teddlie, C., \& Yu, F. (2007). Mixed methods sampling: A typology with examples. Journal of Mixed Methods Research, 1(1), 77-100. DOI 10.1177/1558689806292430.

Valenza, J. K., \& Stephens, W. S. (2015). Challenging Channels: School Librarians \& Evolving Literacies. Journal of Media Literacy, $62(3,4)$.

Yohalem, N., \& Pittman, K. (2003). Public Libraries as Partners in Youth Development: Lessons and Voices from the Field. In Forum for Youth Investment. Forum for Youth Investment. The Cady-Lee House, 7064 Eastern Avenue NW, Washington, DC 20012-2031. 


\section{Appendix 1.}

Questionnaire

First and last name

Birth date

Mobile phone

Email

Library you regularly use

District you live in

1. What is your primary occupation work

study work and study

I don't work

_other

2. For whom do you generally borrow books from the library?

_myself

_ a family member

_a friend

3. How many books do you recall borrowing from the library over the past three months?

4. How many books do you recall reading over the past three months?

5. Aside from reading material you have accessed through the library, through what sources have you accessed reading material over the past three months? (mark all that apply)

_ _ downloaded for free from the Internet

bought on the Internet

bought at a physical store

borrowed or received as a gift

6. What is the main reason you borrowed the books you borrowed from the library over the past three months?

for work and/or professional development

school

to broaden my general knowledge

entertainment 
_other:

7. How often do you visit the library?

more than once a week

once a week

once every two weeks

once a month

once every two months

once or twice a year

less than once a year

8. What type of texts do you prefer reading? (mark all that apply)

novels and/or fiction, indicate categories:

science fiction and/or fantasy

romance

mystery/police/thriller/suspense

terror sagas (TV or film)

_ graphic novels

comics

nonfiction, indicate categories:

history

science

philosophy

politics

poetry

self-help

other:

9. How do you choose the books you read? (mark all that apply)

personal recommendation from a friend

personal recommendation from a teacher, professor, or librarian

reviews and articles in print publications (newspapers, magazines, etc)

mentions in social media

connection to a television series, movie or video I have watched

at random

10. In terms of your reading interests, how would you rate your satisfaction with the variety that your library offers?

very satisfied

satisfied

somewhat satisfied

unsatisfied 
11. Do you participate in any activity associated with books and reading, in or out of the library? No

Yes (mark all that apply)

_ reading club

reading workshop/class

writing workshop/class

other

12. Aside from reading digitized books, what reading- and writing-related activities do you practice online?

reading and writing fanfiction

online fiction or nonfiction writing

massive multiplayer online games

role-playing games

13. Excluding news reading, when you read for pleasure what format do you prefer?

$\ldots$ print

print and digital

digital

14. How often do you

watch traditional TV series

always

watch pay TV series (eg., Netflix) go to the movies

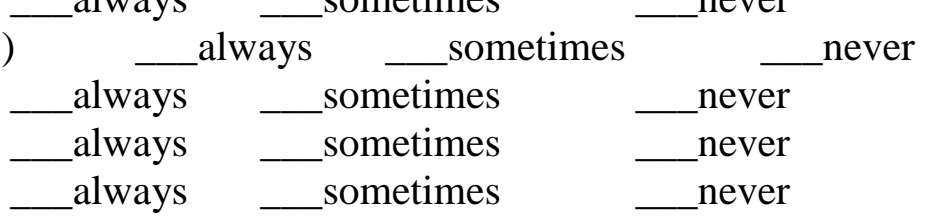
watch videos online always _ _ sometimes never

15. What kinds of books or collections do you feel are missing in the library?

16. What kinds of activities and/or services would you like to see in the library that are not presently available? 